\title{
STERNOBRONCHIAL FISTULA - UNCOMMON COMPLICATION AFTER CORONARY SURGERY (A CASE REPORT)
}

\author{
Jiři Mandák ${ }^{1}$, Vladimír Lonský ${ }^{1}$, Zdeněk Sedláček ${ }^{2}$ \\ University Teaching Hospital in Hradec Králové: Department of Cardiosurgery ${ }^{1}$, Department of Radiology ${ }^{2}$
}

Summary: The authors describe a case of a 46-year-old man with ischemic heart disease who underwent coronary surgery. After some time span an inflamed wound, several skin fistulae and the system of substernal fistulae appeared. One of these fistulae communicated with the left bronchial tree.

Key words: Open-heart surgery; Ischemic heart disease; Sternal osteomyelitis; Sternobronchial fistula

\section{Introduction}

Sternal osteomyelitis ranks among the most serious late complications of the open-heart surgery $(1,5)$. The incidence of this wound complication is smaller than $1.0 \%$ of all cardiac surgery procedures $(2,3)$. An inflammatory fistula communicating from the substernal space to the skin and to the left bronchial tree is rare.

\section{Case report}

This is a case of a 46-year-old man with ischemic heart disease who underwent coronary surgery in 1978. The cardiac operation with cardiopulmonary bypass was standard. Two venous grafts were used for aortocoronary reconstruction (bypasses), but complete revascularization of the myocardium was not performed for diffuse aterosclerosis of coronary arteries. No complications were manifest in the postoperative time during this hospitalisation.

Six years after cardiac surgery procedure an inflamed wound and free-draining pustules along the sternotomy incision appeared. The fistulography didn't show any substernal communication at that time. That was why a radical surgical treatment was prefered. Removal of all wires and stitches, surgical debridement, perfect suction drainage and closed irrigation of antimicrobial and antibiotic solution with the general administration of antibiotics were done.

But the effect of this procedure was temporary only and the other surgical procedures including simple incision, debridement, suction drainage and administration of antibiotics have to be done during subsequent hospitalizations in the next years $(2,3,4)$.

Different types of bacterial pathogens during these hospitalizations were cultivated - Pseudomonas, Acinetobacter, Staphyloccocus aureus, Staphyloccocus epidermidis,
Corynebacterium. No candidal or fungal infections were detected.

The immunodeficience or diabetes mellitus of this patient were not found.

General conditions of this patient were still good (no fever, no bronchopneumonia, no bacteriemia or sepsis, no pain). Nevertheless, two myocardial infarctions that followed worsened his status to CCS III., NYHA II. By that time the ECHO showed left ventricular dysfunction (EF $30 \%)$.

During the last hospitalization in 1997 several skin fistulae and the system of substernal fistulae were found. One of these fistulae communicated with the left bronchial tree.

The fistulography of the cutaneous sternal fistula showed filling of the substernal cavity with contrast medium and the communication with bronchial tree and irregular bronchus affected by chronic inflammatory changes and its communication to the left main bronchus (Fig. 1,2).

CT of the thorax at the level of involved bronchus showed its inflammatory changes and demonstrated the chronic inflammatory changes of the sternum and surrounding tissues (Fig. 3,4).

Staphyloccocus aureus and Corynebacterium diphtheriae were cultivated. The immunodeficience or diabetes mellitus were not found again.

Total excision of the sternum including all corresponding costal cartilages down to the level of pericardium, lung resection and resection of the chest wall and using of muscle flaps would be suggested as a radical surgical treatment.

Due to quite good conditions of otherwise the high-risk patient with a long history of ischemic heart disease (diffuse aterosclerosis of coronary arteries, EF $30 \%$ ) the radical surgery was not performed. The local surgical treatment using wound dressing with administration of antibiotics (local and general) was prefered. 
Fig. 1: Fistulography of cutaneous sternal fistula. Lateral view shows fillinig of substernal cavity with contrast medium (1) and the communication with bronchial tree (2) and irregular bronchus affected by chronic inflammatory changes (3) and its communication to the left main bronchus (4).

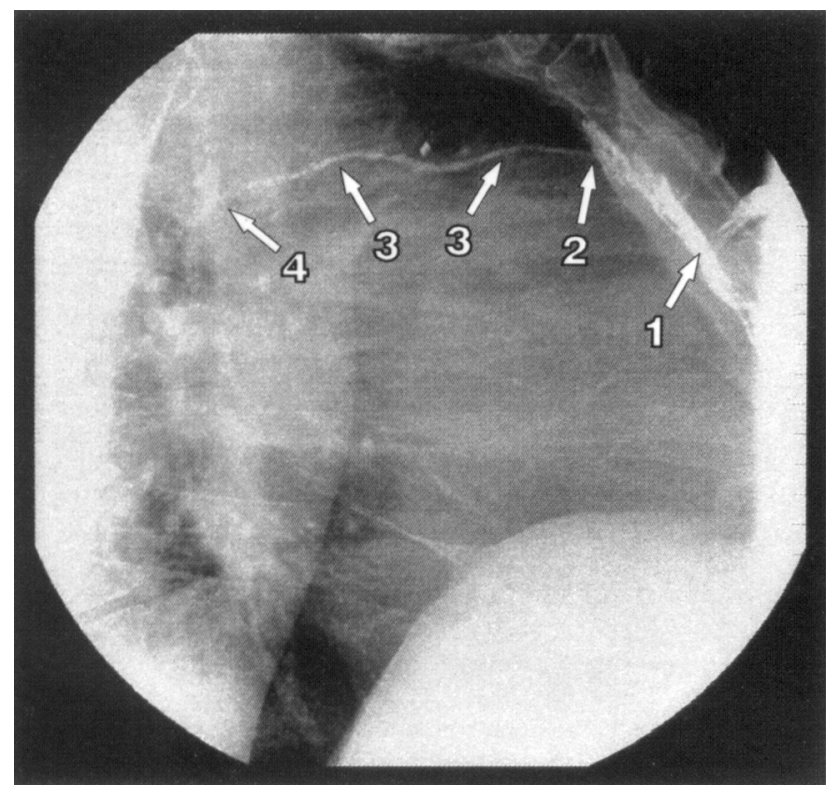

Fig. 2: Fistulography showing the same situation in the right anterior oblique projection.

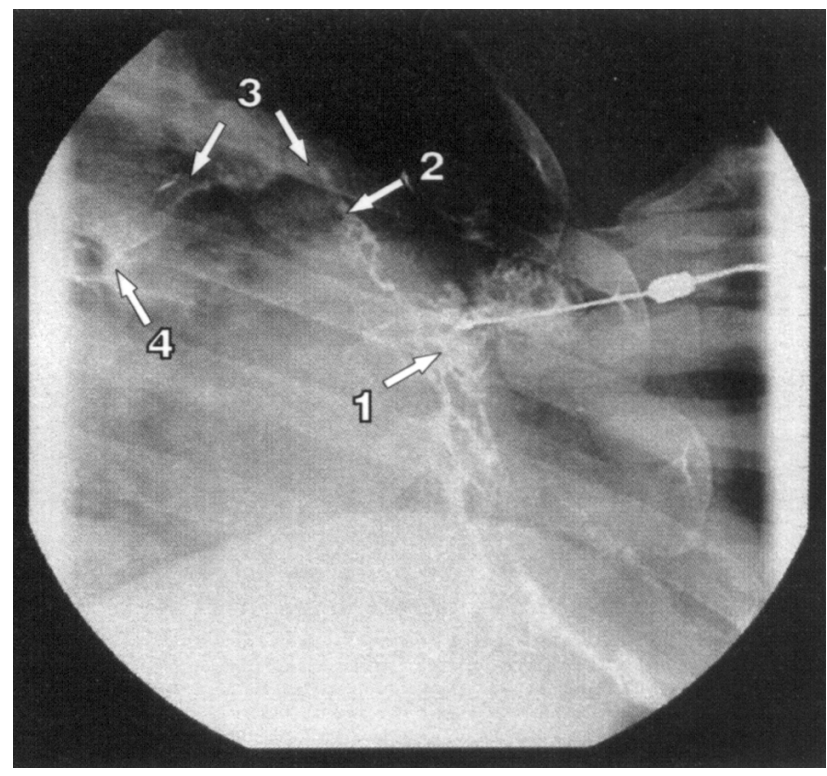

Fig. 3: CT of the thorax (pulmonary window) at the level of involved bronchus (arrows) showing its inflammatory changes.

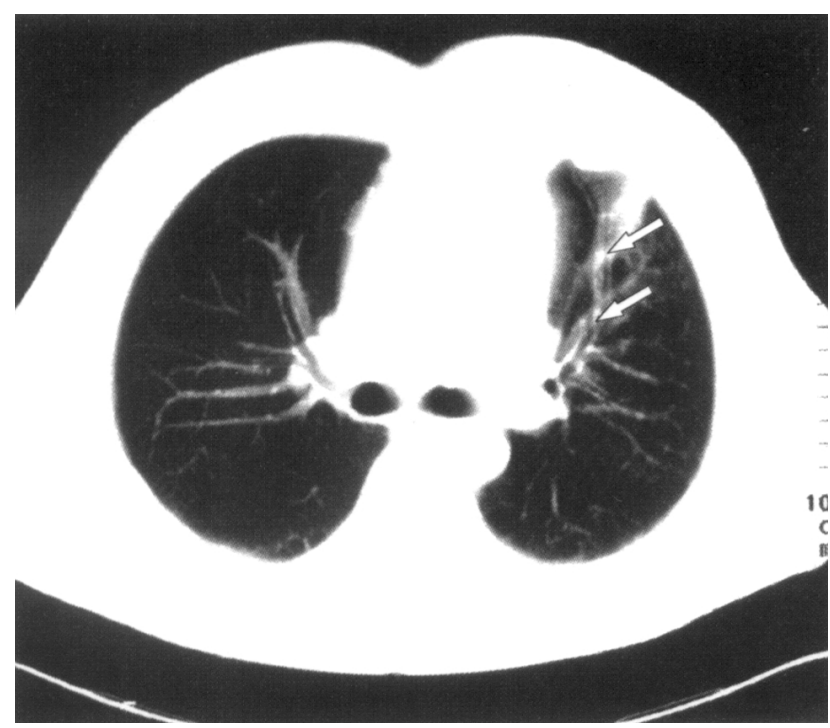

Fig. 4: CT of the thorax (mediastinal window) demonstrates the chronic inflammatory changes of the sternum and surrounding tissues (arrows).

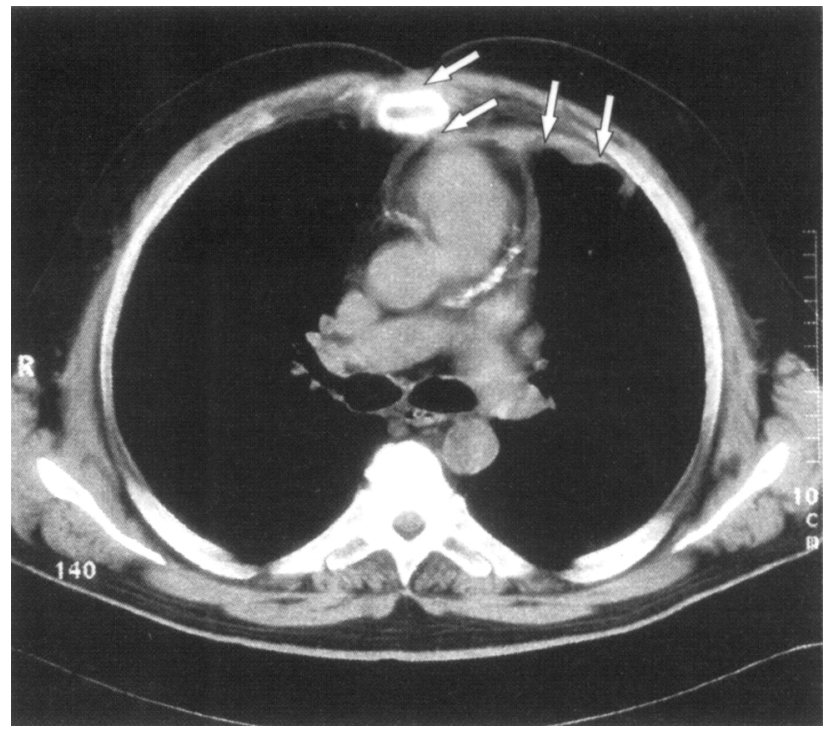


This man died one year later, in 1998. A cause of death was the carcinoma of glandulae suprarenales with metastases to liver.

\section{Conclusion}

The incidence of sternal wound complication (osteomyelitis) is smaller than $1.0 \%$ of all cardiac surgery procedures. A sternobronchial fistula, an inflammatory fistula communicating from the substernal space to the skin and to the left bronchial tree is rare complication after coronary surgery.

The authors felt neccesary to point out this complication of the open-heart surgery as it represents rather rare finding even in the rich clinical material.

\section{References}

1. El Oakley RM, Wright JE. Postoperative mediastinitis: Clasification and management. Ann Thorac Surg 1996;61:1030-6.

2. Durandy Y, Batisse A, Bourel P, Dibie A, Lemoine G, Lecompte Y. Mediastinal infection after cardiac operation. J Thorac Cardiovasc Surg 1989;97:282-5.

3. Lonský V, Štětina M, Rozsíval V, Šimek J, Mandák J, Lonská V. Mediastinitis as a complication of cardiac operations with extracorporeal circulation. Rozhl Chir 1989;68:797-802.

4. Acinapura A, Godfrey A, Romita M, Cunningham J, Adams P, Jacobowitz I Surgical management of infected median sternotomy: closed irrigation vs. muscle flaps. J Cardiovasc Surg 1985;26:443-6.

5 Manifold DK, Large SR. Sternal wound dehiscence after internal mammary artery harvesting. Eur J Cardio-Thorac Surg 1994;8:46-7.

Submitted February 2000.

Accepted March 2000.

MUDr. Jiři Mandák, Ph.D.,

University Teaching Hospital,

Department of Cardiosurgery,

50005 Hradec Králové,

Czech Republic.

e-mail: jiri.mandak@usa.net 